The mode of this patient's infection is uncertain. We think that in walking barefoot she may have trodden in contaminated faeces from an infected person or pet. For a local dog or cat to be chronically infected it would have to have been imported from an endemic area, but larvae might persist and develop in warm, moist soil even in an English summer. It is unlikely that larvae would exist in the soil on contaminated vegetables imported from warmer climes. Orogenital transmission of strongyloidiasis has been suggested, ${ }^{3}$ but this patient denied any sexual contact.

We thank the Department of Medical Helminthology, School of Hygiene and Tropical Medicine, London, for confirming the diagnosis and Professor Grove of the University of Western Australia for his advice.

1 Gill GV, Bell DR, Reid HA. Strongyloidiasis in ex-Far East prisoners of war. BrMed f 1977; 1007. 2 Grove DI. Strongyloidiasis in allied ex-prisoners of war in South East Asia. Br Med f 1980;280: 598-601.

3 Phillips SC, Mildvan D, William DC, Gelb AM, White MC. Sexual transmission of enteric protozoa and helminths in venereal disease clinic population. N Engl F Med 1981;305:603-6.

(Accepted 12 December 1986)

Queen's Medical Centre, Nottingham NG7 2UH

VERONICA SPROTT, MB, MRCP, senior house officer

C D SELBY, BM, MRCP, medical registrar

PURVIN ISPAHANI, MB, FRCPATH, consultant microbiologist

P J TOGHILL, MD, FRCP, consultant physician

Correspondence to: Dr Toghill.

\section{Infection by airborne Chlamydia trachomatis in a dentist cured with rifampicin after failures with tetracycline and doxycycline}

Up to now the transmission of Chlamydia trachomatis, a noted pathogen of the urogenital and conjunctival tracts, has been thought to be by direct contact or exposure to infected mucosae or secretions, as may occur during sexual contact. Airborne transmission of $C$ trachomatis, the usual mode of transmission of Chlamydia psittaci infections, has been documented in only two cases of laboratory infection by $\mathrm{L} 1$ and $\mathrm{L} 2$ strains, which cause lymphogranuloma venereum. ${ }^{\prime}$

We describe three cases of $C$ trachomatis infection resistant to commonly used antibiotics; in one case airborne transmission was probable.

\section{Case reports}

Case 1-In March 1984 a 29 year old doctor began to have ocular burning and pruritus with moderate conjunctival secretion, especially in the morning. Keratoconjunctivitis of a probable viral nature was diagnosed but tests for viruses and bacteria gave negative results. Symptoms persisted with alternating improvement and worsening until January 1985, when he noticed reddening of the glans penis and pruritus of the foreskin. $C$ trachomatis was isolated from the pharynx, conjunctiva, and urethra. Tetracycline given by mouth ( $500 \mathrm{mg}$ four times daily) and topically into the eyes for 10 days was of no avail, and doxycycline $200 \mathrm{mg}$ by mouth daily for 15 days also gave poor results. Rifampicin $(900 \mathrm{mg}$ daily for 15 days $)^{2}$ proved effective.

Case 2-In January 1985 a 27 year old doctor (the wife of case 1) began to have conjunctival burning and reddening, soon followed by vaginal itching, dyspareunia, and leucorrhoea. Conjunctival, pharyngeal, urethral, and cervical specimens were positive for $C$ trachomatis on McCoy cells and by direct immunofluorescence using monoclonal antibodies against the organism. As in case 1 , tetracycline and doxycycline were ineffective, only rifampicin being successful.

Case 3-A 28 year old dentist began treating our first patient five days after he had started doxycycline. The dentist performed a filling over two visits, using surgical gloves and sterile instruments but inadvertently exposing his face to the patient's oral secretions, which became vaporised by diamond tipped cutters mounted on water cooled turbines. Three days later the dentist began to have ocular reddening and itching and, soon afterwards, bilateral purulent conjunctivitis. $C$ trachomatis was isolated from conjunctival and pharyngeal specimens but not from urethral specimens. The dentist was given the same treatment as in cases 1 and 2, only rifampicin proving effective.

In all three cases we obtained definite clearance of clinical symptoms and negative laboratory data for $C$ trachomatis in infected sites, which remained negative several months later.

\section{Comment}

In case 3 transmission of $C$ trachomatis presumably did not occur by direct mucosal contact but by airborne transmission in saliva which became dispersed as an aerosol with water sprayed by the high speed drill. We therefore suggest that dentists should use plastic screens to shield the face from possibly contaminated aerosol droplets created by routinely used dental instruments.

Contamination of the dentist occurred during treatment with doxycycline in case 1. Despite good patient compliance, in none of our cases did doxycycline essentially modify the clinical symptoms or eliminate $C$ trachomatis; this is in contrast with other reports. ${ }^{345}$

Therapeutic failures with tetracycline and doxycycline and success with rifampicin in our three cases should be borne in mind when choosing treatment for $C$ trachomatis infections resistant to commonly used antibiotics. 1 Bernstein DI, Hubbard T, Wenman WM, et al. Mediastinal and supraclavicular lymphadenitis and
pneumonitis due to Chlamydia trachomatis serovars L1 and L2. N Engl f Med 1984;294:1543-7. 2 Schachter J. Rifampin in chlamydial infections. Rev Infect Dis 1983;5(suppl 3):S562-4.

3 Lassus A, Juvakoski T. Treatment of uncomplicated genital Chlamydia trachomatis infections in males. Scand I Infect Dis 1982;32(suppl): 169-72.

4 Oriel JD. The carrier state: Chlamydia trachomatis. J Antimicrob Chemother 1986;18(suppl A): 67-71.

5 Bowie WR. Epidemiology and therapy of Chlamydia trachomatis infections. Drugs 1984;27:459-68.

(Accepted 6fanuary 1987)

La Sapienza University and CNR Institute of Experimental Medicine, Rome, Italy 00161

M MIDULLA, MD, chief of virus laboratory, professor of paediatrics

D SOLLECITO, MD, CNR, fellow

F FELEPPA, medical student

A M ASSENSIO, MD, associate professor of paediatrics

S ILARI, MD, postgraduate student

Correspondence to: Professor Mario Midulla, Institute of Paediatrics, La Sapienza University, Rome, Italy 00161.

\section{Perforation of nasal septum due to button battery lodging in nose}

Increasing attention has been paid recently to tissue necrosis caused by button batteries in contact with mucosal surfaces. I report on a child whose nasal septum perforated when a button battery containing silver oxide lodged in his nose.

\section{Case report}

A 4 year old boy presented to this hospital with a foreign body in his left nostril, which could be seen on examination. He did not have a nasal discharge or pain. As the foreign body could not be removed easily he was given a short general anaesthetic the next day during a routine operating list; a battery (392 Eveready, Sony, Japan) $7.9 \mathrm{~mm}$ in diameter and $3.6 \mathrm{~mm}$ thick was removed, and a blackened area was noted on both sides of the nasal septum where it had been in contact with the battery. On closer examination this area was found to have a small perforation. The battery had probably been in the nose for about 24 hours.

The manufacturer's data showed that the electrolyte in the battery was $25 \%$ potassium hydroxide; the anode contained zinc, $45 \%$ potassium hydroxide, mercury, and CMC (the manufacturer will not disclose what this is); and the cathode contained silver oxide, silver nickel dioxide, and Teflon.

\section{Comment}

A smooth round foreign body lodged in the nose for only a short time would not normally be expected to cause septal perforation. The electrolyte content of this particular battery was $25 \%$ potassium hydroxide. Alkalis are corrosive and damage tissue because of their reaction with protein, saponifying effect on liquids, and necrotic effects on tissue cells. Thus the alkaline content of the battery probably caused the necrosis.

Ear, nose, and throat clinics will probably see increasing numbers of patients with button batteries as foreign bodies: the batteries are widely used not only in hearing aids, cameras, and calculators but also in electronic games, which are popular with children. Swallowing of such batteries is becoming more common, ${ }^{1-3}$ and two deaths due to oesophageal perforation have been reported. ${ }^{45} \mathrm{I}$ recommend that button batteries lodged in a body cavity are removed as a matter of urgency. 
I acknowledge the help of Mr R J Sergeant and Mr J L Steinberg.

1 Yasu I, Noriyki I, Satoru S. Magnetic removal of alkaline batteries from the stomach. $\mathcal{F}$ Pediatr Surg 1985;20:250-1.

2 Reilly DT. Mercury battery ingestion. Br Med $\mathcal{F}$ 1979; 8559

3 D'Sa EAB, D'Sa AABB. Mercury battery ingestion. Br Med f 1979; 1218.

4 Shabic CL, Feinberg AN. Oesophageal perforation secondary to alkaline battery ingestion. foumal of the American College of Emergency Physicians and University Association for Emergency Medicine 1979;8:360-2.

5 Blatnik DS, Toonhill RJ, Leham RH. Fatal complication from an alkaline battery foreign body in the oesophagus. Ann Otol Rhinol Laryngol 1977;86:611-5.

(Accepted 23 fanuary 1987)

Kent and Sussex Hospital, Tunbridge Wells, Kent TN4 8AT

$P$ FERNANDO, MB, BS, senior house officer in ear, nose, and throat surgery

Correspondence to: Dr P Fernando, Harrogate General Hospital, Harrogate HG2 7ND.

\section{How complete is a total parathyroidectomy in uraemia?}

Hyperparathyroidism is common in chronic renal failure and despite recent medical advances parathyroidectomy is often required. Subtotal parathyroidectomy was performed originally ${ }^{1}$ but because of the risks of recurrent hyperparathyroidism due to hyperplasia of the gland remnant total parathyroidectomy was then recommended, especially in patients destined for long term dialysis. ${ }^{2}$ We report the long term follow up of a group of patients receiving maintenance haemodialysis who were subjected to total parathyroidectomy.

\section{Patients, methods, and results}

Between 1973 and 1976, 12 patients receiving maintenance haemodialysis underwent total parathyroidectomy for severe renal bone disease. Seven long term survivors form the basis of this report. In each of these cases four

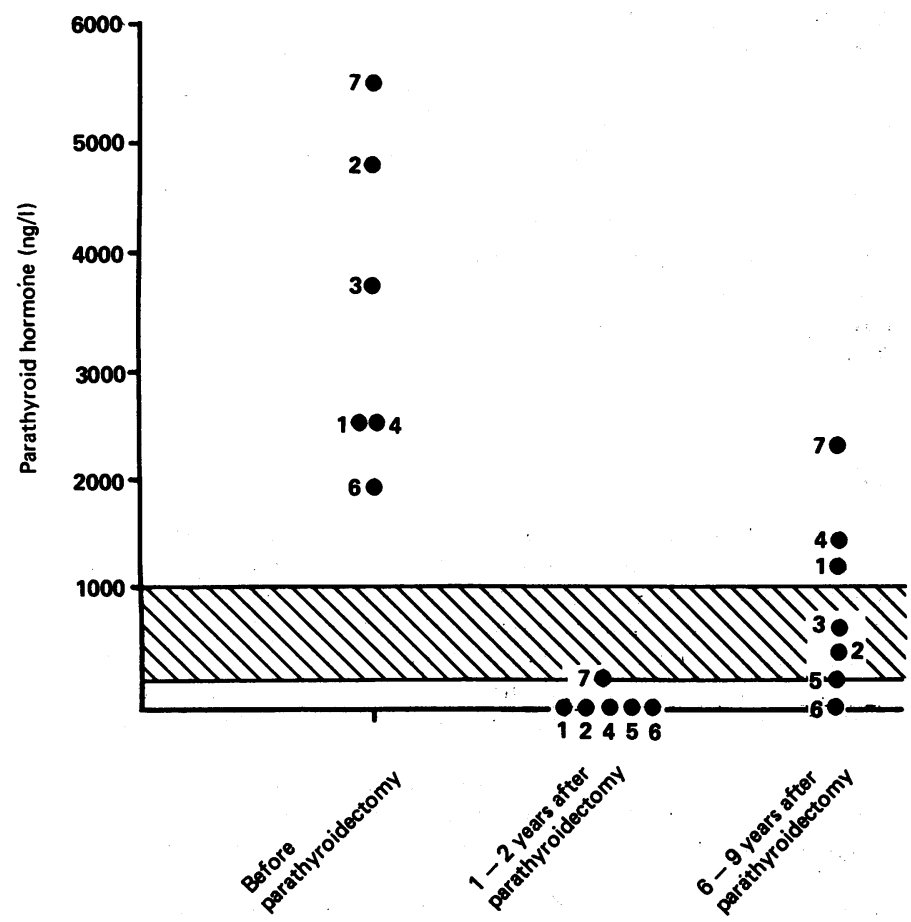

Immunoreactive parathyroid hormone concentrations before total parathyroidectomy and one to nine years afterwards. Hatched area denotes upper and lower limits of normal range. Numbers refer to individual cases. hyperplastic parathyroid glands were removed at operation and confirmed histologically. Immediately postoperatively hypocalcaemia occurred in all patients despite treatment with calcium and vitamin $D$ analogues. Plasma alkaline phosphatase activities, which were raised before operation (mean 387 (SEM 123) KA units/1; normal 30-130), returned to normal within one year in six patients (mean activity at one year 94 (19) KA/l). Plasma hydroxyproline concentrations, which were also high preoperatively (mean 20.5 (SEM 7.3) mg/l; normal $1 \cdot 1-2 \cdot 4$ ), fell more quickly in all patients (mean concentration at one month $4.5(1.0) \mathrm{mg} / \mathrm{l})$. Treatment with calcium and vitamin $\mathrm{D}$ compounds was continued in the long term after operation, the doses being tailored to maintain normal plasma calcium concentrations.

Plasma immunoreactive parathyroid hormone concentrations (measured by radioimmunoassay using Wellcome antibody AS211/32) were obtained preoperatively in six patients and were raised in all (figure). Repeat estimations were obtained in six patients one to two years after total parathyroidectomy. In five patients immunoreactive parathyroid hormone was undetectable but in the sixth the concentration was at the lower limit of normal. Further estimates of immunoreactive parathyroid hormone concentrations were obtained in all patients six to nine years after total parathyroidectomy. At that stage immunoreactive parathyroid hormone was undetectable in only one patient (case 6; figure) and was present in normal concentrations in three patients (cases 2,3, and 5 ), and three patients had frankly raised values (cases 1, 4, and 7). Four patients still required maintenance haemodialysis at final follow up (cases $1,3,4$, and 7); three of these had raised immunoreactive parathyroid hormone concentrations and two had symptomatic bone disease (cases 1 and 7), both of whom had subperiosteal erosions radiologically. Three patients had renal transplants that were functioning well at the time of final follow up (cases 2,5 , and 6 ). In one of these immunoreactive parathyroid hormone was undetectable and two had concentrations in the normal range. None had clinical or radiological evidence of hyperparathyroidism.

\section{Comment}

There were many indications that the removal of four hyperplastic glands in our patients initially resulted in severe hypoparathyroidism. The occurrence of hypocalcaemia despite calcium supplements and vitamin D analogues and the finding of undetectable immunoreactive parathyroid hormone concentrations in five of six patients one to two years after total parathyroidectomy suggest that for some time after total parathyroidectomy there was no effective secretory parathyroid tissue in these patients. These data suggest, however, that detectable immunoreactive parathyroid hormone may be usual six to nine years after total parathyroidectomy and that frankly raised concentrations may also occur. Though some $2 \%$ to $6 \%$ of patients may have supernumerary parathyroid glands, ${ }^{3}$ it is unlikely that hyperplastic supernumerary glands could account for the high incidence of recovery of parathyroid function found in most of our patients. This may be the explanation of our patient (case 7) who had detectable concentrations of immunoreactive parathyroid hormone one year after parathyroidectomy. The likely explanation for the return of parathyroid function in the remaining patients was hyperplasia of small fragments of parathyroid gland left behind at total parathyroidectomy.

Also interesting was that patients who continued with haemodialysis throughout follow up were those in whom concentrations of immunoreactive parathyroid hormone were highest at the end of follow up, whereas those with successful renal transplants had low or undetectable concentrations. This suggests that the uraemic state is the main stimulus to hyperplasia of the remnant parathyroid tissue.

1 Stanbury JW, Lumb GA, Nicholson WF. Elective subtotal parathyroidectomy for renal hyperparathyroidism. Lancet 1960;i:793-8.

$2 \mathrm{Ogg}$ CS. Total parathyroidectomy in the treatment of secondary (renal) hyperparathyroidism. Br Med f 1967;iv:331-4.

3 Wang C, Mahaffey JE, Axelrod L, Perlman JA. Hyperfunctioning supernumerary parathyroid glands. Surg Gynecol Obstet 1979;148:711-4.

(Accepted 19 January 1987)

Department of Nephrology and Transplantation, Royal Free Hospital, London NW3 20G

K FARRINGTON, MD, MRCP, consultant physician

Z VARGHESE, MSC, PHD, top grade biochemist and associate director of renal research unit

M K CHAN, MSC, FIMLS, senior medical laboratory scientific officer

O N FERNANDO, FRCS, consultant surgeon

R A BAILLOD, $\mathrm{MB}, \mathrm{BS}$, first assistant

P SWENY, MD, FRCP, senior lecturer and consultant physician

J F MOORHEAD, FRCP, consultant nephrologist and director of department of nephrology and transplantation

Correspondence to: Dr Varghese. 